\title{
Making tobacco control a priority
}

\author{
Anita Dessaixa,b,g, Becky Freemanc,d and Matthew J Peters ${ }^{e, f}$ \\ a Cancer Prevention and Advocacy, Cancer Council NSW, Sydney, Australia \\ b Public Health Committee, Cancer Council Australia, Sydney, NSW \\ c Prevention Research Collaboration, School of Public Health, Sydney Medical School, University of Sydney, NSW, Australia \\ d Charles Perkins Centre, University of Sydney, NSW, Australia \\ e Faculty of Medicine, Health and Human Sciences, Macquarie University, Sydney, NSW, Australia \\ † Department of Thoracic Medicine, Concord Hospital, Sydney, NSW, Australia \\ ${ }^{g}$ Corresponding author: anita.dessaix@nswcc.org.au
}

\section{Article history}

\section{Publication date: September 2020}

Citation: Dessaix A, Freeman B, Peters MJ.

Making tobacco control a priority. Public Health Res Pract. 2020;30(3):e3032015. https://doi.org/10.17061/phrp3032015

\section{Background}

This issue of Public Health Research \& Practice builds on the 2019 Oceania Tobacco Control Conference theme, 'Making tobacco control a priority'. The conference, held in Sydney before the COVID-19 pandemic, brought together record numbers of researchers, advocates, policy makers and administrators from Australia, New Zealand and Pacific Island nations. Although the Oceania region has had incredible success in reducing smoking rates, smoking will not simply fade out on its own. Fresh approaches and a commitment to continuing to implement what we know works in tobacco control is crucial.

Our goal is to rid decision makers of any sense of complacency around tobacco control policy and practice. Debunking the myth that we are now only dealing with a 'hard-core group' of committed smokers must be part of this renewal strategy. While it may be tempting to think 'mission accomplished', there is much more work still to do.

This issue coincides with historically low smoking rates in Australia. The number of daily smokers aged older than 14 years has fallen significantly, with $11 \%$ of Australians reporting daily smoking in 2019 - down from $12.2 \%$ in $2016 .{ }^{1} \mathrm{~A}$ further $63 \%$ of Australians say they have never smoked, with that figure increasing to almost $97 \%$ among those younger than 18 years. ${ }^{1}$

Evidence-based tobacco control measures have contributed to these decades-long declines. Key measures adopted include: large-scale investment in quit-smoking campaigns, restrictions on tobacco advertising, health warnings on tobacco packaging, real increases in the price of tobacco and smoke-free environments. ${ }^{2}$ Grogan and Banks ${ }^{3}$, and Brooks et al. ${ }^{4}$ critique the status of some of these key measures and outline what's missing from our approach.

Although smoking rates are now lower, the health toll remains high. Two in three continuing smokers will die prematurely from smoking-related disease ${ }^{5}$, and yet tobacco products remain readily accessible in all our communities. For this special issue, we invited authors to consider where we should go from here for tobacco control, giving consideration to the many innovative policy and practice approaches presented at the 2019 Oceania Tobacco Control Conference. 


\section{Where to next in tobacco control?}

The World Health Organization Framework Convention on Tobacco Control (FCTC) commits signatories to take evidence-based action to address tobacco-related harm. ${ }^{6}$ Article 5.3 of the treaty requires parties to protect public health policies from commercial and other vested interests of the tobacco industry. Despite this, tobacco industry interference stalls policy making, perpetuates conflicted research and spreads false information. ${ }^{7.8} \mathrm{Big}$ Tobacco's latest ploy includes an attempt to reposition itself as pivotal to health improvement, social and economic development ${ }^{9}$, through the expansion and marketing of its product offerings. ${ }^{10}$ In this issue, Daube ${ }^{11}$ examines expanding the application of Article 5.3 to other non-government health groups, including academic institutions and conferences.

Tobacco use is a primary contributor to health inequity, with smoking rates highest among low socio-economic groups ${ }^{1}$ and vulnerable populations, including Aboriginal and Torres Strait Islander people. Encouragingly, smoking prevalence among Aboriginal and Torres Islander people has fallen from $55 \%$ in 1994 to $43 \%$ in 2018-19.12 Thomas and Calma ${ }^{13}$ review achievements and current limitations in decreasing tobacco use among Aboriginal and Torres Strait Islander people across different states and territories, and those living in metropolitan versus regional and remote areas.

Overwhelmingly, smokers (63\%) want to quit. Less than one-third of Australian smokers report that they do not plan to quit, with this proportion remaining unchanged over the past decade. ${ }^{1}$ Cigarette cost and health concerns are cited as the primary reasons for motivating quit attempts. Despite this, in 2019, three in 10 smokers tried and failed to successfully quit. Smoking cessation is "the single, most powerful, preventive intervention" available in clinical practice ${ }^{14}$ and has been comprehensively implemented in some countries for some time..$^{15}$ Yet in Australia, when a patient comes into contact with the health system, the systematic identification and recording of smoking status is still not consistently occurring. Patients are not being provided with advice and support to quit - a potentially life-saving intervention. As argued by White et al. ${ }^{16}$, smokers must be supported with evidence-based measures to quit, including access to tobacco cessation treatment, and further investment in smoking cessation support is needed.

Smoking rates among youth and young adults have never been lower. ${ }^{17}$ Across Australia, today's generation of young adults have grown up as children exposed to powerful antismoking campaigns. The first National Tobacco Campaign was hard-hitting in approach and between 1997 and 2001, was coupled with unprecendented financial investment from the Australian Government, and state and territory organisations. ${ }^{18}$ In more recent years, investment in public education campaigns has fluctuated nationally and between states and territories. ${ }^{19}$ There are more media channels and fragmented audiences, which in turn is adding pressure to what advertising dollars are available. Despite these challenges, we know investment in quality media campaigns at high enough levels can continue to encourage quitting behaviours and also improve equity in cessation outcomes. ${ }^{20}$ Beasley et al. ${ }^{21}$ build on existing evidence and provide practical insights on where we can direct future campaign efforts.

\section{Looking to the future for tobacco control}

Moves to address the commercial supply of tobacco products have gained momentum globally, as outlined in a plenary by Ruth Malone of the University of California, San Francisco, at the 2019 Oceania Tobacco Control Conference. 22,23 Tobacco retail licensing schemes are becoming increasingly commonplace and calls to ban the sale of products close to schools and in neighbourhoods are growing. ${ }^{24}$ Reducing the supply of tobacco products, with an eye to removing them completely from retail sale, may seem a bridge too far, but the same was said of plain packaging for tobacco products. ${ }^{25}$

Fears that chronic disease prevention will be put aside during the COVID-19 pandemic further fuel the need to renew investment in tobacco control. As part of South Africa's response to the COVID-19 pandemic, tobacco products were deemed a 'non-essential' consumer good during lockdown and were abruptly made unavailable for legal purchase. ${ }^{26}$ The COVID-19 pandemic has also seen reported record numbers of UK citizens quit smoking in light of the link between smoking and likelihood of suffering from severe coronavirus illness. ${ }^{27}$ Public health concerns need not compete with each other; both the COVID-19 pandemic and tobacco use can be concurrently and effectively addressed.

We hope readers enjoy the themed papers and all the articles within this issue, and they are useful as we consider next steps in tobacco control and our long-term goal of a smoke-free Oceania.

\section{Acknowledgements}

This themed issue of Public Health Research \& Practice was supported by and developed in partnership with Cancer Council Australia.

\section{Peer review and provenance}

Internally reviewed, invited. 


\section{Competing interests}

AD was chair of the 2019 Oceania Tobacco Control Conference organising committee. BF was chair of the 2019 Oceania Tobacco Control Conference program committee, and her travel and accommodation expenses were reimbursed to attend the conference. The conference was hosted by Cancer Council NSW. BF is also an expert advisor to the Cancer Council Australia and Heart Foundation Australia Tobacco Issues Committee.

\section{Author contributions}

$A D$ and $B F$ contributed equally to writing and editing the article. MP contributed to the article and was responsible for reviewing.

\section{References}

1. Australian Institute of Health and Welfare. National Drug Strategy Household Survey 2019. Canberra: AlHW; 2020 [cited 2020 Aug 18]. Available from: www.aihw.gov.au/ getmedia/3564474e-f7ad-461c-b918-7f8de03d1294/ aihw-phe-270-NDSHS-2019.pdf.aspx?inline=true

2. Scollo M, Winstanley M. Tobacco in Australia: facts and issues. Melbourne: Cancer Council Victoria; 2012 [cited 2020 Aug 13]. Available from: www.tobaccoinaustralia. org.au/introduction

3. Grogan P, Banks E. Far from 'mission accomplished': time to re-energise tobacco control in Australia. Public Health Res Pract. 2020;30(3):e3032016.

4. Brooks A, Oakes W, Buchanan T. Smoke-free environments: current status and remaining challenges in Australia. Public Health Res Pract. 2020;30(3):e3032022.

5. Banks E, Joshy G, Weber MF, Liu B, Grenfell R, Egger S, et al. Tobacco smoking and all-cause mortality in a large Australian cohort study: findings from a mature epidemic with current low smoking prevalence. BMC Med. 2015;13:38.

6. WHO Framework Convention on Tobacco Control. Geneva; WHO: 2003 [cited 2020 Aug 18]. Available from: www.who.int/fctc/text_download/en/

7. Stopping Tobacco Organizations and Products. Tobacco Tactics: University of Bath; Updated July 2020 [cited 202014 Aug ]. Available from: tobaccotactics.org/wiki/ covid-19/

8. Gilmore AB, Fooks G, Drope J, Bialous SA, Jackson RR. Exposing and addressing tobacco industry conduct in low-income and middle-income countries. Lancet. 2015;385(9972):1029-43.

9. Philip Morris International. Sustainability. Neuchâtel, Switzerland: Philip Morris Products SA; 2020 [cited 2020 Aug 14]. Available from: www.pmi.com/sustainability
10. British American Tobacco. Our products. London: BAT; 2020 [cited 2020 Aug 14]. Available from: www.bat. com/group/sites/UK_9D9KCY.nsf/vwPagesWebLive/ D052AD6X

11. Daube M. The WHO Framework Convention on Tobacco Control - time for a civil society equivalent? Public Health Res Pract. 2020;30(3):e3032018.

12. Australian Institute of Health and Welfare. Alcohol, tobacco \& other drugs in Australia. Canberra: AlHW; 2020 [updated 26 June 2020; cited 2020 Aug 14]. Available from: www.aihw.gov.au/reports/alcohol/ alcohol-tobacco-other-drugs-australia/contents/prioritypopulations/aboriginal-and-torres-strait-islander-people

13. Thomas D, Calma T. Tackling Indigenous smoking: a good news story in Australian tobacco control. Public Health Res Pract. 2020;30(3):e3032019.

14. Woolf $\mathrm{SH}$. The need for perspective in evidence-based medicine. JAMA. 1999;282(24):2358-65.

15. Reid RD, Pipe AL, Quinlan B. Promoting smoking cessation during hospitalization for coronary artery disease. Can J Cardiol. 2006;22(9):775-80.

16. White SL, McCaffrey N, Scollo MM. Tobacco dependence treatment in Australia - an untapped opportunity for reducing the smoking burden. Public Health Res Pract. 2020;30(3):3032020.

17. Dessaix A, Maag A, McKenzie J, Currow DC. Factors influencing reductions in smoking among Australian adolescents. Public Health Res Pract. 2016;26(1):e2611605.

18. Hill D, Carroll T. Australia's National Tobacco Campaign. Tob Control. 2003;12 Suppl 2:ii9-14.

19. Carroll T, Cotter T, Purcell K, Bayly M. Public education campaigns to discourage smoking: the Australian experience. In: Greenhalgh E, Scollo M, Winstanley M, editors. Tobacco in Australia: Facts and issues. Melbourne: Cancer Council Victoria; 2019.

20. Durkin SJ, Biener L, Wakefield MA. Effects of different types of antismoking ads on reducing disparities in smoking cessation among socioeconomic subgroups. AM J Pubic Health. 2009;99(12):2217-23.

21. Beasley SJ, Barker A, Murphy M, Roderick T, Carroll T. What makes an effective antismoking campaign insights from the trenches. Public Health Res Pract. 2020;30(3):e3032021.

22. Malone R. The "third rail": isn't it time to start talking about phasing out cigarette sales? Oceania Tobacco Control Conference; 2019 October 22-24; Doltone House, Sydney. Sydney: Cancer Council NSW; 2019 [cited 2020 Aug 25]. Available from: otcc.org.au/ QuickEventWebsitePortal/2019/agenda/Agenda/ AgendaltemDetail?id=f056c45e-c098-414e-a147$01 \mathrm{ee} 9 \mathrm{c} 4 \mathrm{e} 2 \mathrm{e} 80$

23. Smith EA, Malone RE. An argument for phasing out sales of cigarettes. Tob Control. 2019;tobaccocontrol-2019-055079. 
24. Coxe N, Webber W, Burkhart J, Broderick B, Yeager K, Jones $L$, et al. Use of tobacco retail permitting to reduce youth access and exposure to tobacco in Santa Clara County, California. Prev Med. 2014;67 Suppl 1:S46-50.

25. Freeman B. Tobacco plain packaging legislation: a content analysis of commentary posted on Australian online news. Tob Control. 2011;20(5):361-6.

26. Cilliers C. Tobacco association announces it will launch a legal challenge of cigarette ban. Johannesburg: The Citizen; 2020 Apr 17 [cited 2020 Aug 13]. Available from: citizen.co.za/business/business-news/2271089/tobaccoassociation-announces-it-will-launch-a-legal-challengeof-cigarette-ban/

27. Schraer R. Coronavirus: smokers quit in highest numbers in a decade; 2020 Jul 15. London: BBC; 2020 [cited 2020 Aug 8]. Available from: www.bbc.com/news/ health-53403610

\section{Copyright: (C) (i) (2) (2)}

(C) 2020 Dessaix et al. This article is licensed under the Creative Commons Attribution-NonCommercial-ShareAlike 4.0 International Licence, which allows others to redistribute, adapt and share this work non-commercially provided they attribute the work and any adapted version of it is distributed under the same Creative Commons licence terms. See: www.creativecommons.org/licenses/by-nc-sa/4.0/ 